\title{
Linked color imaging confers benefits in profiling $H$. pylori infection in the stomach
}

\section{다 $(9)$}

\section{Authors}

Xiaotian Sun ${ }^{*}, 1,2$, Yiliang $\mathrm{Bi}^{*}{ }^{*}$, Bing Nong ${ }^{3}$, Duanmin $\mathrm{Hu}^{4}$, Xiaomin Sun ${ }^{5}$, Honglei Chen ${ }^{6}$, Yang $\mathrm{Xu}^{1}$, Yan Liu ${ }^{1}$

Institutions

1 Department of Gastroenterology, the Fifth Clinical Center of Chinese PLA General Hospital (307 Hospital), Beijing, China

2 Department of Internal Medicine, Clinic of August First Film Studio, Beijing, China

3 Department of Gastroenterology and Hepatology, the People's Hospital of Guangxi Zhuang Autonomous Region, Nanning, China

4 Department of Gastroenterology, the Second Affiliated Hospital of Soochow University, Suzhou, China

5 Department of Gastroenterology and Hepatology, Shanghai Tenth People's Hospital, Shanghai, China

6 Department of Gastroenterology, the Sixth Affiliated Hospital of Sun Yat-sen University, Guangzhou, China.

submitted 23.10.2018

accepted after revision 14.2.2019

Bibliography

DOI https://doi.org/10.1055/a-0895-5377 |

Endoscopy International Open 2019; 07: E885-E892

(c) Georg Thieme Verlag KG Stuttgart · New York

eISSN 2196-9736

Corresponding author

Yan Liu, Department of Gastroenterology, The Fifth Clinical

Center of Chinese PLA General Hospital (307 Hospital),

Beijing 100071, China

Fax: +86-010-66927473

13911798288@163.com

Supplementary Material: Fig. 1,2, Table 1

Online content viewable at:

https://doi.org/10.1055/a-0895-5377

\section{ABSTRACT}

Background and study aims There is a high prevalence of Helicobacter pylori infection. White light endoscopy (WLE) can be used for evaluating the mucosal lesions, but it does not have high diagnostic efficiency. Linked color imaging $(\mathrm{LCl})$ is a newly developed endoscopic imaging technique. The aim of this study was to compare LCl with WLE in detecting and staging $H$. pylori infection in the stomach in a randomized controlled clinical trial.

Patients and methods A total of 253 patients who had indications for gastroduodenoscopy were enrolled and randomized into Group A ( $n=127)$, who underwent WLE followed by LCl, and Group B ( $n=126)$, who underwent LCI followed by WLE. Clinical data were collected and the diagnostic accuracy of WLE and LCI was calculated and compared. Results The overall diagnostic accuracy of WLE and LCI for H. pylori infection was $31.5 \%(n=40)$ and $50.4 \%(n=64)$ in Group A $(P=0.001)$, and $36.5 \%(n=46)$ and $49.2 \%(n=62)$ in Group $B(P=0.029)$. In both groups, LCl had higher sensitivity, specificity, and Youden index scores than WLE. Four stages were defined in the course of $H$. pylori infection in the stomach. $\mathrm{LCl}$ staging results were more highly consistent with pathological staging than were WLE staging results (kappa value 0.772 vs. 0.516 ). The $\mathrm{LCl}$ observations were closely correlated with the pathology.

Conclusion LCl had a higher diagnostic efficacy for $\mathrm{H}$. pylori infection in the stomach. Endoscopic color features under $\mathrm{LCl}$ can help to stage and profile $\mathrm{H}$. pylori-associated gastritis.

\section{Clinical.Trials.gov}

NCT02724280

TRIAL REGISTRATION: Multi-center double-blinded randomized controlled trial NCT02724280 at clinicaltrials.gov

\section{Introduction}

Prevalent worldwide, Helicobacter pylori infection can increase risk of gastric cancer and is associated with the occurrence of a variety of human diseases, including lymphoma and autoim-

\footnotetext{
* These authors contributed equally.
}

mune disorders [1,2]. $H$. pylori infection is most common in the stomach, and patients with it may have heartburn, epigastric pain, dyspepsia, and other nonspecific symptoms, which are easily overlooked in a majority of cases [3]. Diagnosis of $H$. pylori infection can be made based on judgment of the clinical manifestation, detection of a specific antibody in serum, 
and based on results of a $\mathrm{C}^{13}$ breath test $[4,5]$. In addition, endoscopic examination may provide useful evidence for confirming the diagnosis, and tissue from biopsy performed under endoscopy can be sent for a rapid urease test and pathology.

Inflammation, atrophy, and intestinal metaplasia of the gastric mucosa caused by presence of $H$. pylori have different appearances under endoscopy $[6,7]$. However, changes in mucosa observed under white light endoscopy (WLE) are not distinctive, and the stages of $H$. pylori infection in the stomach rarely have been reported. Linked color imaging ( $\mathrm{LCl})$ is a color-enhanced technique, which enables easier identification of mucosal lesions during endoscopy by significantly improving color contrast between lesions and normal tissue [8,9]. Our previous data validated that $\mathrm{LCl}$ can greatly improve endoscopic diagnostic accuracy of gastrointestinal mucosal lesions $[10,11]$, while the role of $\mathrm{LCl}$ endoscopy in evaluating and staging $\mathrm{H}$. pylori infection in the stomach has not been clearly investigated. In the current study, we conducted a randomized controlled clinical trial (RCT) to compare the diagnostic efficiency of WLE and $\mathrm{LCl}$ for $\mathrm{H}$. pylori infection and further analyzed the endoscopic characteristics of different stages. The findings will help optimize current management of patients with $H$. pylori infection.

\section{Patients and methods}

\section{Patients}

Consecutive adult patients who had indications and underwent gastroduodenoscopy between September 2016 and February 2017 were enrolled from five endoscopic centers: Affiliate Hospital to Academy of Military Medical Science (307 Hospital; the Fifth Clinical Center of Chinese PLA General Hospital), the People's Hospital of Guangxi Zhuang Autonomous Region, Shanghai Tenth People's Hospital, the Second Affiliated Hospital of Soochow University and the Sixth Affiliated Hospital of Sun Yat-sen University. Patients who had thrombocytopenia (platelet count $<50,000 / \mu \mathrm{L}$ ) or elevated International Normalized Ratio (INR > 1.5), hemodynamic instability, pregnancy and lactation, had ever undergone $H$. pylori eradication therapy, or were unable or unwilling to give an informed consent were excluded. Demographic and clinical data were retrieved from the computerized database.

All patients gave informed consent. The study was approved by the Ethics Committee of Affiliate Hospital to Academy of Military Medical Science. This study was registered at ClinicalTrials.gov (ClinicalTrials.gov ID: NCT02724280). We had access to the study data and had reviewed and approved the final manuscript.

\section{Study design}

The flow chart of this RCT is shown in Supplemental Fig. 1. McNemar test was used to calculate the sample size by using SPSS software. The sample size was calculated based on a probability of 0.8 and $\alpha$ error of 0.05 . The actual expected sensitivity of $\mathrm{LCl}$ and WLE for diagnosing $\mathrm{H}$. pylori was around $80 \%$ and $45 \%$ according to our previous study and experience $[10,12]$. The required sample size was set to 250 patients. 253 patients were enrolled. All patients were randomized into Group $A(n=$ $127)$ or Group $B(n=126)$ at a $1: 1$ ratio using the random number method. The random sequence was generated by Excel and concealed. In Group A, patients received WLE followed by $\mathrm{LCI}$ endoscopic examination. In Group B, patients received $\mathrm{LCl}$, followed by WLE mode for gastroscopy. This study was doubleblind, and patients and endoscopists were not informed of the grouping information, which was achieved by the participation of a third endoscopist who intubated and withdrew the endoscopy.

\section{Procedures}

All endoscopic procedures were performed under anesthesia. EG-L590WR endoscopes equipped with the LASEREO endoscopic system (FUJIFILM Co., Tokyo, Japan) were used. WLE and $\mathrm{LCl}$ examinations were conducted by two different endoscopists who had comparable skills and experience with endoscopic examinations. No magnification was applied. The biopsies were completed by a third endoscopist for the purposes of conducting a rapid urease test and histological examination. According to the Sydney System [13], two biopsies from lesser and greater curvature (around $8 \mathrm{~cm}$ from the cardia), two biopsies from the pre-pyloric antrum $(3-5 \mathrm{~cm}$ from the pylorus), and one biopsy from the gastric angle were taken in each case. $H$. pylori infection was manifested as diffuse or spotty red with nodularity and enlarged/tortuous folds under WLE, and red mixed with heterogeneous purple under $\operatorname{LCl}[12,13]$. To minimize the inconsistency of diagnostic accuracy among different endoscopists, typical endoscopic images of LCI and WLE were distributed to train the participating endoscopists.

\section{Outcomes}

Diagnosis of $H$. pylori infection was made by positivity in a rapid urease test and/or histological examination of any of the biopsies in one patient. If rapid urease test and the histological examination were all negative in all the biopsies of one patient, it was judged as $H$. pylori infection-negative. Overall diagnostic efficacy evaluation was performed and the receiver operating characteristic (ROC) curve was drawn. The sensitivity, specificity, negative predictive value (NPV), positive predictive value (PPV), and Youden index of WLE and $\mathrm{LCl}$ in Groups $\mathrm{A}$ and $\mathrm{B}$ were calculated in the diagnostic test, respectively. $H$. pylori infection in the stomach was comprehensively determined by histological analysis or rapid urease test, which was administered for all patients. Overall diagnostic efficacies of WLE and $\mathrm{LCI}$ in diagnosing $H$. pylori infection in the stomach were compared. $H$. pylori infection in different parts of the stomach was analyzed for profiling the stages. Kappa values were calculated for the correlation analysis of pathological staging with WLE staging and $\mathrm{LCl}$ staging.

\section{Statistical analysis}

All statistical analyses were conducted using SPSS 17.0 software (SPSS Inc., Chicago, Illinois, United States). Continuous and categorical data were presented as means (range) and percentages (\%), respectively. Data were analyzed using independent $t$-test and Chi-square or Fisher's exact probability test, if 
- Table 1 Demographic and clinical characteristics.

\begin{tabular}{|c|c|c|c|c|}
\hline & Group A $(n=127)$ & Group B $(n=126)$ & $t / x^{2}$ & $P$ value \\
\hline Age, years, mean (range) & $47.20(19-76)$ & $49.66(19-72)$ & 1.540 & 0.125 \\
\hline Gender, $n(\%)$ & & & 0.102 & 0.750 \\
\hline Male & $66(52.0)$ & $68(54.0)$ & & \\
\hline Female & $61(48.0)$ & $58(46.0)$ & & \\
\hline Indications, $n(\%)$ & & & 7.178 & 0.127 \\
\hline Heartburn & $19(15.0)$ & $17(13.5)$ & & \\
\hline Abdominal distension & $21(16.5)$ & $32(25.4)$ & & \\
\hline Dyspepsia & $15(11.8)$ & $14(11.1)$ & & \\
\hline Epigastric pain & $23(18.1)$ & $31(24.6)$ & & \\
\hline Other & $49(38.6)$ & $32(25.4)$ & & \\
\hline \multicolumn{5}{|c|}{ H. pylori infection evaluation, $n(\%)$} \\
\hline Rapid urease test & & & 0.005 & 0.941 \\
\hline Positivity & $54(42.5)$ & $53(42.1)$ & & \\
\hline Negativity & $73(57.5)$ & $73(57.9)$ & & \\
\hline Histological examination & & & 0.001 & 0.970 \\
\hline H. pylori infection & $34(26.8)$ & $34(27.0)$ & & \\
\hline No H. pylori infection & $93(73.2)$ & $92(73.0)$ & & \\
\hline WLE diagnosis & & & 0.708 & 0.400 \\
\hline H. pylori infection & $40(31.5)$ & $46(36.5)$ & & \\
\hline No H. pylori infection & $87(68.5)$ & $80(63.5)$ & & \\
\hline LCl diagnosis & & & 0.674 & 0.412 \\
\hline H. pylori infection & $64(50.4)$ & $57(45.2)$ & & \\
\hline No H. pylori infection & $63(49.6)$ & $69(54.8)$ & & \\
\hline
\end{tabular}

applicable. Two-tailed $P$ values less than 0.05 were considered statistically significant.

\section{Results}

\section{Demographic and clinical characteristics}

There were 127 patients in Group A and 126 patients in Group $B$. There were no significant differences in age, gender, or indications for endoscopy between the two groups (all $P>0.05$, - Table 1). Rapid urease test, histology, WLE, and LCI were applied for evaluating $H$. pylori infection in the stomach. The detection rate for $H$. pylori infection, which was around $27.0 \%$ to $50.4 \%$, was comparable in Group A and Group B (all $P>0.05$, - Table 1). A total of 107 patients with $\mathrm{H}$. pylori infection were finally diagnosed by rapid urease test and/or histology.

\section{Diagnostic efficacy for $H$. pylori infection}

H. pylori infection in the stomach was independently evaluated by WLE followed by LCI in Group A, and by LCI followed by WLE in Group B ( $\triangleright$ Fig. 1). The overall diagnostic accuracy of WLE and $\mathrm{LCl}$ in Group A $(n=127)$ were $31.5 \%(n=40)$ and $50.4 \%$ $(n=64)$, respectively $(P=0.001)$, while the overall diagnostic accuracy of WLE and LCI were $36.5 \%(n=46)$ and $49.2 \%(n=62)$ in Group B ( $n=126 ; P=0.029)$. In addition, the ROC curve of $\mathrm{LCl}$ and WLE for $H$. pylori infection was analyzed (Supplemental Fig. 2). The results were consistent in indicating that $\mathrm{LCI}$ had higher diagnostic efficacy for $H$. pylori infection than did WLE. In both groups, LCl had higher sensitivity, specificity, NPV, PPV, and Youden index than did WLE. The AUC for WLE and LCI was 0.542 and 0.850 in Group $A$, and 0.559 and 0.891 in Group B ( $>$ Table 2$)$. 


\section{Group A}

Gastric antrum
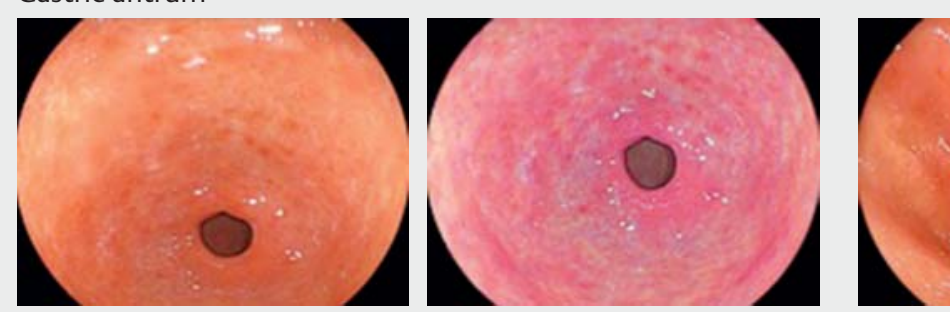

Group B

\section{Gastric body}
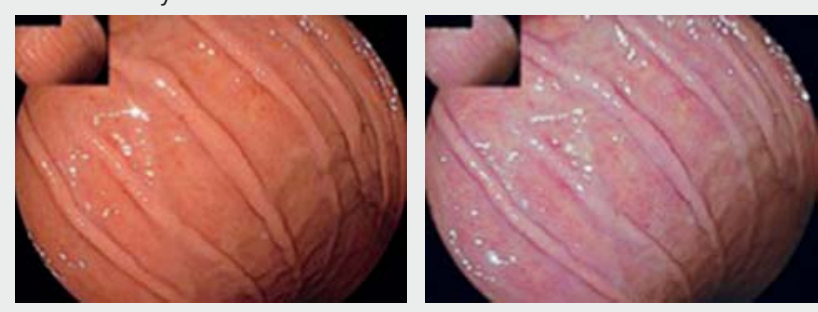

WLE
LCI

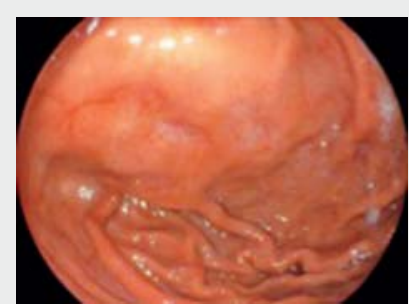

WLE

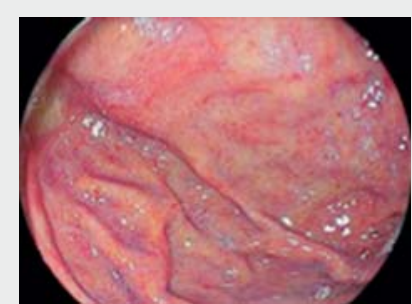

$\mathrm{LCl}$

Fig. 1 Typical endoscopic images for $H$. pylori infection in the stomach.

- Table 2 Diagnostic efficacy evaluation of WLE and LCI for H. pylori infection.

\begin{tabular}{|c|c|c|}
\hline & Group $A(n=127)$ & Group B $(n=126)$ \\
\hline \multicolumn{3}{|l|}{ WLE } \\
\hline AUC ( $P$ value) & $0.542(0.416)$ & $0.559(0.256)$ \\
\hline Sensitivity, \% (95\% Cl) & $35.8(27.5-44.1)$ & $43.4(34.7-52.1)$ \\
\hline Specificity, \% (95\% CI) & $72.6(64.8-80.4)$ & $68.5(60.4-76.6)$ \\
\hline NPV, $\%(95 \% \mathrm{CI})$ & $48.7(40.0-57.4)$ & $50.0(41.3-58.7)$ \\
\hline PPV, \% (95\% CI) & $60.9(52.4-69.4)$ & $62.5(54.0-71.0)$ \\
\hline Youden index, \% (95\% Cl) & $8.4(3.6-13.2)$ & $11.9(6.2-17.6)$ \\
\hline \multicolumn{3}{|l|}{$\mathbf{L C l}$} \\
\hline AUC ( $P$ value $)$ & $0.850(<0.001)$ & $0.891(<0.001)$ \\
\hline Sensitivity, \% (95\% Cl) & $90.6(85.5-95.7)$ & $90.6(85.5-95.7)$ \\
\hline Specificity, \% (95\% Cl) & $79.5(72.5-86.5)$ & $87.7(82.0-93.4)$ \\
\hline NPV, $\%(95 \% \mathrm{Cl})$ & $76.2(68.8-83.6)$ & $84.2(77.8-90.6)$ \\
\hline PPV, \% (95\% CI) & $92.1(87.4-96.8)$ & $92.8(88.3-97.3)$ \\
\hline Youden index, \% (95\% CI) & $70.1(62.1-78.1)$ & $78.3(71.1-85.5)$ \\
\hline \multicolumn{3}{|c|}{$\begin{array}{l}\text { WLE, white light endoscopy; AUC, area under the curve; } \mathrm{Cl} \text {, confidence in- } \\
\text { terval; NPV, negative predictive value; PPV, positive predictive value; } \mathrm{LCl} \text {, } \\
\text { linked color imaging }\end{array}$} \\
\hline
\end{tabular}

\section{$\mathrm{LCl}$ could determine stage of $H$. pylori infection in the stomach}

Distribution of $\mathrm{H}$. pylori infection and morphological changes in the stomach mucosa may evolve during the course of disease. This kind of evidence may help determine the stage, about which little is known. Thus, we analyzed data from 107 patients with confirmed $H$. pylori infection and investigated that infection in the gastric body and antrum together with pathological changes ( $\triangleright$ Table 3 ). According to previous reports [14-16], $H$. pylori infection commonly starts in the gastric antrum, migrates into the gastric body, and then spreads throughout the entire stomach (gastric body and antrum). During the course of infection, incidences of atrophy and intestinal metaplasia in gastric antrum were noticeably increased.

We further hypothesized that $H$. pylori infection may have four stages: 1) Stage $1, H$. pylori infection in the antrum without intestinal metaplasia; 2) Stage 2, $H$. pylori infection in the antrum and body without intestinal metaplasia; 3) Stage 3, intestinal metaplasia in the antrum and $H$. pylori infection in the body; and 4) Stage 4, both intestinal metaplasia and $H$. pylori infection in the antrum and body. However, in some patients, infection could not be staged and they were thus classified as Stage X (indeterminable). Different stages had different endoscopic appearances ( $>$ Fig. 2). LCl staging yielded greater consistency with pathological staging than did WLE staging (Kappa value 0.772 vs. 0.516 , Table 4). Of 16 patients with $\mathrm{LCl}$ Stage $X, 12$ were pathological Stage $X$ and four were pathological Stage 4. Under LCI mode, the inflammation appeared as diffusive red, mucosal atrophy appeared as white, and intestinal 
Table 3 H. pylori infection in different parts of the stomach.

\begin{tabular}{|l|l|l|l|l|}
\hline & $\begin{array}{l}\text { No } \mathbf{H .} \text { pylori infection } \\
(\mathbf{n = 1 4 6 )}\end{array}$ & $\begin{array}{l}\text { H. pylori infection in } \\
\text { gastric antrum (n=64) }\end{array}$ & $\begin{array}{l}\text { H. pylori infection in } \\
\text { gastric body (n=9) }\end{array}$ & $\begin{array}{l}\text { H. pylori infection in gastric } \\
\text { body and antrum (n=34) }\end{array}$ \\
\hline Gastric body, $n(\%)$ & & $0(0.0)$ & $0(0.0)$ & $0(0.0)$ \\
\hline Atrophy & $16(11.0)$ & $3(4.7)$ & $1(11.1)$ & $2(5.9)$ \\
\hline Intestinal metaplasia & $26(17.8)$ & & & $4(11.8)$ \\
\hline Gastric antrum, $n(\%)$ & & $3(4.7)$ & $2(22.2)$ & $11(32.4)$ \\
\hline Atrophy & $13(8.9)$ & $11(17.2)$ & $2(22.2)$ & \\
\hline Intestinal metaplasia & $31(21.2)$ & &
\end{tabular}

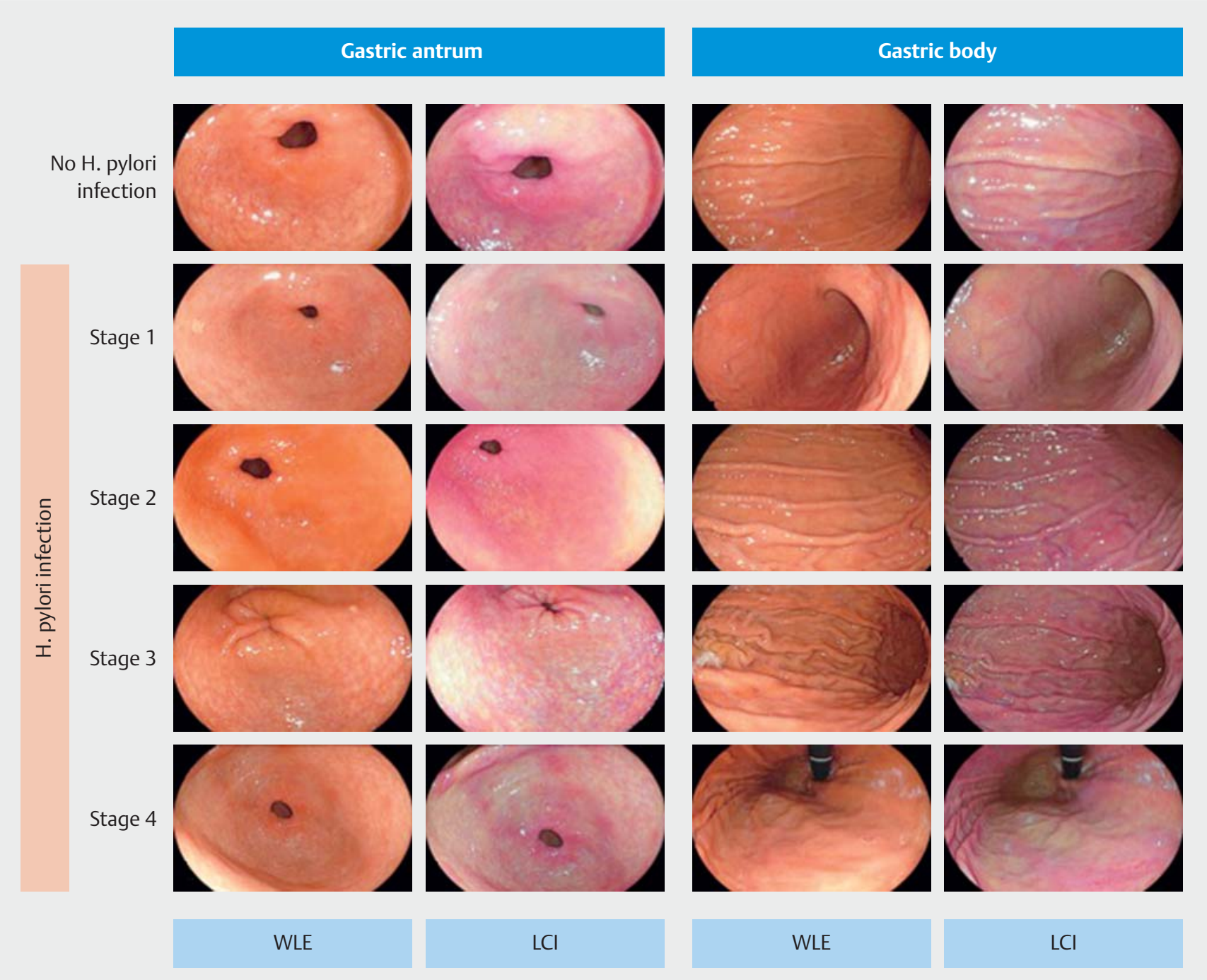

- Fig. 2 Typical endoscopic images of $H$. pylori infection-associated gastritis at different stages. In Stage $1, H$. pylori infection was observed mainly in the gastric antrum; it can gradually spread into the gastric body in Stage 2. In Stage 3, along with H. pylori-associated inflammation in the mucosa, intestinal metaplasia was found in the antrum. Intestinal metaplasia characterized by presence of goblet cells in the epithelial layer was the main feature of the mucosa of the gastric body in Stage 4; the inflammation can be subtle. 
Table 4 Stages in the course of H. pylori infection in the stomach.

\begin{tabular}{|c|c|c|c|c|c|c|c|c|c|c|c|c|}
\hline & & \multicolumn{5}{|c|}{ WLE staging, $\mathbf{n}$} & \multicolumn{5}{|c|}{ LCl staging, $\mathbf{n}$} & \multirow[t]{2}{*}{ Total, $\mathbf{n}$} \\
\hline & & $\begin{array}{l}\text { Stage } \\
1\end{array}$ & $\begin{array}{l}\text { Stage } \\
2\end{array}$ & $\begin{array}{l}\text { Stage } \\
3\end{array}$ & $\begin{array}{l}\text { Stage } \\
4\end{array}$ & $\begin{array}{l}\text { Stage } \\
\mathrm{X}\end{array}$ & $\begin{array}{l}\text { Stage } \\
1\end{array}$ & $\begin{array}{l}\text { Stage } \\
2\end{array}$ & $\begin{array}{l}\text { Stage } \\
3\end{array}$ & $\begin{array}{l}\text { Stage } \\
4\end{array}$ & $\begin{array}{l}\text { Stage } \\
\mathrm{X}\end{array}$ & \\
\hline \multirow{5}{*}{$\begin{array}{l}\text { Pathologi- } \\
\text { cal staging, } \\
\text { n }\end{array}$} & Stage 1 & 30 & 2 & 0 & 0 & 0 & 28 & 4 & 0 & 0 & 0 & 32 \\
\hline & Stage 2 & 8 & 15 & 2 & 1 & 0 & 4 & 22 & 0 & 0 & 0 & 26 \\
\hline & Stage 3 & 0 & 1 & 9 & 2 & 0 & 0 & 0 & 10 & 2 & 0 & 12 \\
\hline & Stage 4 & 3 & 1 & 1 & 7 & 11 & 0 & 0 & 3 & 16 & 4 & 23 \\
\hline & Stage $X$ & 0 & 2 & 1 & 5 & 6 & 0 & 0 & 0 & 2 & 12 & 14 \\
\hline \multirow{2}{*}{\multicolumn{2}{|c|}{ Total, n }} & 41 & 21 & 13 & 15 & 17 & 32 & 26 & 13 & 20 & 16 & 107 \\
\hline & & \multicolumn{5}{|c|}{ Карра $=0.516, P<0.001$} & \multicolumn{5}{|c|}{ Карра $=0.772, P<0.001$} & \\
\hline
\end{tabular}

WLE, white light endoscopy; LCI, linked color imaging

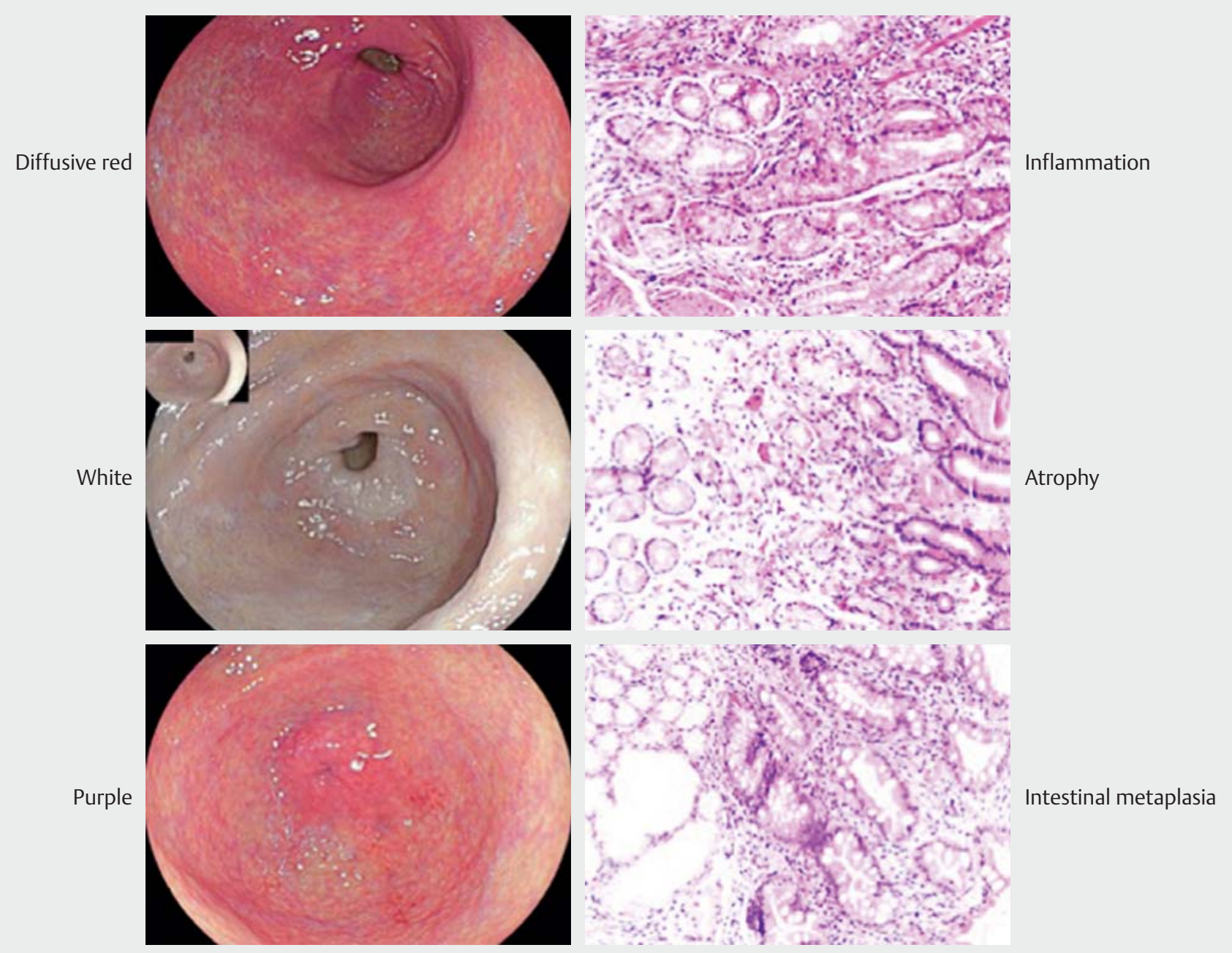

- Fig. $3 \mathrm{LCl}$ findings were closely associated with the pathology. 
metaplasia appeared as purple (Supplemental Table 1). The LCI observations were closely correlated with the pathology ( $\triangleright$ Fig. 3). During LCl endoscopy, purple was associated with intestinal metaplasia $(P=0.025)$ and diffusive red was associated with inflammation $(P=0.016)$. As intestinal metaplasia is a typical mucosal change in $H$. pylori infection, presence of red ringed with purple under $\mathrm{LCl}$ can predict $H$. pylori infection in the stomach $(P=0.022)$. This provides a rapid and convenient evaluation for screening the stomach. However, no such correlations were found under WLE mode.

\section{Discussion}

Gastric mucosa infected with $H$. pylori can undergo a series of pathological changes, including inflammation, atrophy, and intestinal metaplasia $[17,18]$. A single-center study reported that $H$. pylori-associated gastritis was connected with endoscopic modifications and histopathology in a prospective cohort of children [19]. It was also shown that the conventional endoscopy features can be used to diagnose $H$. pylori [20-22], but the efficiency of WLE was relatively poor [23,24]. Endocytoscopy may facilitate in vivo gastric mucosal histopathology [25], but it is time-consuming and some patients cannot tolerate it. However, whether endoscopy can be used to predict these kinds of mucosal lesions, a question that has been rarely explored in a randomized setting, remains unclear [2]. In the current study, we compared the diagnostic efficacy of WLE and $\mathrm{LCl}$ in a multicenter RCT, and for the first time propose that observation of red ringed with purple under $\mathrm{LCl}$ mode could predict diagnosis of $H$. pylori infection in the stomach.

$\mathrm{LCl}$ is a recently developed endoscopic technique that incorporates image post-processing into the laser endoscopic system [26]. LCI makes it easier for endoscopists to identify color changes in the gastrointestinal mucosa by enhancing color contrast. Our previous study demonstrated that $\mathrm{LCl}$ can improve the efficiency and accuracy of differentiating gastrointestinal mucosal lesions and improve the performance of target biopsies [10]. Calculation of pixel brightness based on a red-greenblue color model may be introduced as an objective evaluator for analyzing typical endoscopic images. Consistently, we also correlated color features under LCI with pathology. Statistical analysis validated that a purple color observed under $\mathrm{LCl}$ could predict existence of intestinal metaplasia, and red predicts observation of inflammation. However, analysis of the correlation between atrophy and a white color under $\mathrm{LCl}$ was not conducted, due to the small number of patents with atrophy. Sensitivity of $\mathrm{LCl}$ for diagnosis of $H$. pylori infection was similar to previous studies, but that of WLI was quite low compared to the previous studies [8], and the possible reasons may be the different clinical practice in different medical institutions and the selected sample.

H. pylori infection, which is considered a precancerous lesion, is an independent risk factor for gastric cancer [27]. Gastroduodenoscopy is well known as an effective strategy for early detection of gastric mucosal lesions [28-30]. Our staging system was mainly based on comprehensive analysis of endoscopic images in different locations. Our data profiled four stages of $H$. pylori infection in the stomach. In Stage $1, H$. pylori infection was observed mainly in the gastric antrum; it can gradually spread into the gastric body in Stage 2. In Stage 3, along with $\mathrm{H}$. pylori-associated inflammation in the mucosa, intestinal metaplasia was found in the antrum. Intestinal metaplasia characterized by presence of goblet cells in the epithelial layer was the main feature of the mucosa of the gastric body in Stage 4; the inflammation can be subtle. We then further calculated incidence of $H$. pylori infection in different parts of the stomach, and investigated the respective pathological changes. Of 107 patients with $H$. pylori infection in the stomach, there were 64 patients $(59.8 \%)$ with $H$. pylori infection only in the gastric antrum, nine $(8.4 \%)$ with $H$. pylori infection only in the gastric body, and $3431.2 \%$ ) with $\mathrm{H}$. pylori infection in both the gastric body and antrum ( $\vee$ Table 3 ). Intestinal metaplasia and atrophy occurred more often in the gastric antrum than in the gastric body. Typical color changes under $\mathrm{LCl}$ were highly consistent with the pathology (purple for intestinal metaplasia, $P=0.025$; diffusive red for inflammation, $P=0.016$ ). In addition, we validated LCl staging by comparing WLE staging in terms of its correlation with pathological staging. $\mathrm{LCl}$ had higher consistency with pathological staging than did WLE staging. However, 16 patients could not be staged by LCI (LCI Stage X), 12 of whom could not be staged by pathology due to atypical pathological changes (pathological Stage X). All of the patients were older than age 30 year, and no other special demographical and clinical characteristics were detected.

There were limitations in our study. First, patients who had ever undergone $H$. pylori eradication therapy were excluded. Thus, our staging method could not be used for them. Second, our conclusion was obtained based on the findings in a patient cohort, which may be further validated in a large-scale clinical trial. The main limitation in this study was that the role of $\mathrm{LCl}$ in surveillance of patients with $H$. pylori infection was not examined. Follow-ups will be further investigated in future research. It was expected that the endoscopic and histological features could help screen for gastric mucosal changes after eradication of $H$. pylori infection [31,32].

\section{Conclusion}

From this multicenter RCT, we conclude that LCI has higher diagnostic efficacy for evaluating $H$. pylori infection in the stomach than does WLE, and this new endoscopic technique can be used as an effective method for quick diagnosis. Correlation analysis with pathology indicated that red ringed with purple observed under $\mathrm{LCl}$ could predict presence of $H$. pylori infection. In addition, this staging system can help clarify development of $H$. pylori infection in the stomach, which might have benefits for clinical management of such disease.

\section{Competing interests}

None 


\section{References}

[1] Leja M, Axon A, Brenner H. Epidemiology of Helicobacter pylori infection. Helicobacter 2016; 21: (Suppl. 01): $3-7$

[2] O'Connor A, O'Morain CA, Ford AC. Population screening and treatment of Helicobacter pylori infection. Nat Rev Gastroenterol Hepatol 2017; 14: $230-240$

[3] Inoue M. Changing epidemiology of Helicobacter pylori in Japan. Gastric Cancer 2017; 20: 3-7

[4] Megraud F, Floch P, Labenz J et al. Diagnostic of Helicobacter pylori infection. Helicobacter 2016; 21: (Suppl. 01): 8-13

[5] Tongtawee T, Kaewpitoon S, Kaewpitoon N et al. Diagnosis of Helicobacter pylori Infection. Asian Pac J Cancer Prev 2016; 17: 1631- 1635

[6] Backert S, Neddermann M, Maubach G et al. Pathogenesis of Helicobacter pylori infection. Helicobacter 2016; 21: (Suppl. 01): 19-25

[7] Pimentel-Nunes P, Libanio D, Lage J et al. A multicenter prospective study of the real-time use of narrow-band imaging in the diagnosis of premalignant gastric conditions and lesions. Endoscopy 2016; 48: $723-730$

[8] Dohi O, Yagi N, Onozawa $Y$ et al. Linked color imaging improves endoscopic diagnosis of active Helicobacter pylori infection. Endosc Int Open 2016; 4: E800 - 805

[9] Fukuda H, Miura Y, Hayashi Y et al. Linked color imaging technology facilitates early detection of flat gastric cancers. Clin J Gastroenterol 2015; 8: 385-389

[10] Sun X, Dong T, Bi Y et al. Linked color imaging application for improving the endoscopic diagnosis accuracy: a pilot study. Scientific reports 2016; 6: 33473

[11] Min M, Deng P, Zhang W et al. Comparison of linked color imaging and white-light colonoscopy for detection of colorectal polyps: a multicenter, randomized, crossover trial. Gastrointest Endosc 2017; 86: $724-730$

[12] Sun X, Bi Y, Dong T et al. Linked colour imaging benefits the endoscopic diagnosis of distal gastric diseases. Sci Rep 2017; 7: 5638

[13] Khakoo SI, Lobo AJ, Shepherd NA et al. Histological assessment of the Sydney classification of endoscopic gastritis. Gut 1994; 35: 1172 1175

[14] Kato T, Yagi N, Kamada T et al. Diagnosis of Helicobacter pylori infection in gastric mucosa by endoscopic features: a multicenter prospective study. Dig Endosc 2013; 25: 508-518

[15] Sugano K, Tack J, Kuipers EJ et al. Kyoto global consensus report on Helicobacter pylori gastritis. Gut 2015; 64: $1353-1367$

[16] Nomura S, Ida K, Terao $S$ et al. Endoscopic diagnosis of gastric mucosal atrophy: multicenter prospective study. Dig Endosc 2014; 26: 709- 719

[17] Kamboj AK, Cotter TG, Oxentenko AS. Helicobacter pylori: the past, present, and future in management. Mayo Clin Proc 2017; 23: 216
[18] Mitchell H, Katelaris P. Epidemiology, clinical impacts and current clinical management of Helicobacter pylori infection. Med J Aust 2016; 204: $376-380$

[19] Marginean CO, Cotoi OS, Pitea AM et al. Assessment of the relationship between Helicobacter pylori infection, endoscopic appearance and histological changes of the gastric mucosa in children with gastritis (a single center experience). Rom J Morphol Embryol 2013; 54: $709-715$

[20] Mao T, Wang Y, Yin F et al. Association of endoscopic features of gastric mucosa with Helicobacter pylori infection in Chinese patients. Gastroenterol Res Pract 2016; 2016: 6539639

[21] Ribeiro IC, Kubrusly LF, Nassif PA et al. Relationship between the presence of Helicobacter pylori with inflammatory endoscopic changes in gastroduodenal mucosa. Arq Bras Cir Dig 2016; 29: 142 145

[22] Gomes A, Skare TL, Prestes MA et al. Conventional videoendoscopy can identify Helicobacter pylori gastritis? Arq Bras Cir Dig 2016; 29: $73-76$

[23] Matrakool L, Tongtawee T, Bartpho T et al. improved detection of Helicobacter pylori infection and premalignant gastric mucosa using conventional white light source gastroscopy. Asian Pac J Cancer Prev 2016; 17: 2099-2103

[24] Liu KS, Wong IO, Leung WK. Helicobacter pylori associated gastric intestinal metaplasia: treatment and surveillance. World J Gastroenterol 2016; 22: $1311-1320$

[25] Sato $\mathrm{H}$, Inoue $\mathrm{H}$, Ikeda $\mathrm{H}$ et al. In vivo gastric mucosal histopathology using endocytoscopy. World J Gastroenterol 2015; 21: 5002 - 5008

[26] Okada M, Sakamoto H, Takezawa T et al. Laterally spreading tumor of the rectum delineated with linked color imaging technology. Clin Endosc 2016; 49: 207 - 208

[27] Pourhoseingholi MA, Vahedi M, Baghestani AR. Burden of gastrointestinal cancer in Asia; an overview. Gastroenterol Hepatol Bed Bench 2015; 8: 19-27

[28] Sato H, Inoue H, Hayee B et al. In vivo histopathology using endocytoscopy for non-neoplastic changes in the gastric mucosa: a prospective pilot study (with video). Gastrointest Endosc 2015; 81: 875-881

[29] Anagnostopoulos GK, Yao K, Kaye P et al. High-resolution magnification endoscopy can reliably identify normal gastric mucosa, Helicobacter pylori-associated gastritis, and gastric atrophy. Endoscopy 2007; 39: $202-207$

[30] Lee YC, Lin JT. Screening and treating Helicobacter pylori infection for gastric cancer prevention on the population level. J Gastroenterol Hepatol 2017; 32: 1160 - 1169

[31] Saka A, Yagi K, Nimura S. Endoscopic and histological features of gastric cancers after successful Helicobacter pylori eradication therapy. Gastric Cancer 2016; 19: 524-530

[32] Suzuki S, Gotoda T, Suzuki H et al. Morphologic and Histologic changes in gastric adenomas after Helicobacter pylori eradication: a long-term prospective analysis. Helicobacter 2015; 20: 431-437 